

lowa State University does not discriminate on the basis of race, color, age, religion, national origin, sexual orientation, gender identity, genetic information, sex, marital status, disability, or status as a U.S. veteran. Inquiries can be directed to the Director of Equal Opportunity and Compliance, 3280 Beardshear Hall, (515) 294-7612. 


\title{
ENDOGENOUS BORROWING CONSTRAINTS AND WEALTH INEQUALITY
}

\section{Joydeep Bhattacharya \\ Xue Qiao \\ Tsinghua University \\ Min Wang \\ Peking University}

October 19, 2014

\begin{abstract}
This paper studies the evolution of wealth inequality in an economy with endogenous borrowing constraints. In the model economy, agents need to borrow to finance human capital investments but cannot commit to repaying their loans. Creditors can punish defaulters by banishing them permanently from the credit market. In equilibrium, loan default is prevented by imposing a borrowing limit tied to the borrower's inheritance. The heterogeneity in inheritances translates into heterogeneity in the borrowing limits: endogenously, some young borrowers face a zero borrowing limit, some are partly constrained, while others are unconstrained. Depending on the initial distribution of inheritances, it is possible all lineages are attracted to either the zero-borrowing-limit steady state or to the unconstrained-borrowing steady state - long-run equality. It is also possible some lineages end up at one steady state and the rest at the other - complete polarization. Interestingly, the wealth dynamics in the model closely resemble that in the seminal work of Galor and Zeira (1993).
\end{abstract}

JEL Classification Numbers: E62, E25, O23, O41, E44.

Keywords: wealth inequality, endogenous borrowing constraints, exclusion 


\section{Introduction}

Around the time of the Industrial Revolution, human capital started to replace physical capital as the primary source of economic growth. (Galor and Moav, 2004) Ever since, world over, economic agents in the early part of their lifecycle have sought to make substantial investments in human capital via expenditures on education. Such investments come with a promise of high future earnings, and for most people, the path to a high standard of living. In modern times, such investments are often intermediated via a credit market. Loan contracts between a borrower and a lender are written up and both parties commit to the terms offered and restrictions imposed by signing the contract. If contractual obligations are not met, by either party, the affected agent can seek justice and compensation from the legal system in place: in modern societies, the job of contract enforcement lies with the legal system.

But what of a world in which the contracting parties cannot commit to the terms they agreed on and the legal system, in its role as enforcer, is largely absent or prohibitively costly to access? Do credit markets cease to function in that case? In this paper, we study such a world, one in which the legal environment, for whatever reason, cannot be relied upon to enforce loan contracts. The act of loan-making is always fraught with the risk of non-repayment; in a world sans a strong rule of law, that risk is intensified by the lack of institutions that punish defaulters.

In our stylized vision of that world, loan defaulters cannot be hauled to court. However, creditors, collectively, can exclude defaulters from future participation in the credit market. To those borrowers content with spending the rest of their lives in financial autarky, this threat is not particularly serious. For all others, this threat matters. And it is this threat that helps reign in potentially-recalcitrant borrowers and places limits on borrowing based on evidence of borrowers' self-interest to repay. In such a world, many who seek funds are either turned away or receive less than what they would like. ${ }^{1}$ What impact does all this have on aggregate human capital investment? Does inequality matter for credit market activity? How does inequality evolve over time? More generally, how does the economy with a perfect legal system match up to with one in which the legal system is virtually absent? These are the sorts of questions we wish to address in this paper.

Formally, this paper investigates the evolution of inequality in a world characterized by endogenous borrowing constraints on human capital investment. To that end, we study a three-period overlapping-generations model with fixed factor prices, wherein agents invest in education when young and reap its benefits when middle-aged. As parents, old-age agents are

\footnotetext{
${ }^{1}$ This sort of "credit rationing" can, of course, emerge in models with perfect legal systems and imperfect capital markets plagued by some type of informational impurity (e.g., moral hazard) or asymmetry (such as, adverse selection).
} 
assumed to receive warm glow utility from leaving a bequest to their middle-age children. The only source of heterogeneity among middle-aged agents is the inheritance they receive. By design, young agents need to borrow in imperfect capital markets to invest in human capital and they may use their inheritance, along with other income, to pay off their education loans. As in Kehoe and Levine (1993) and Azariadis and Lambertini (2003), the capitalmarket imperfection manifests itself in the inability of borrowers to commit to repaying education loans. By assumption, a creditor cannot seize a borrower's private, inalienable endowment, nor his human capital; the only enforceable penalty for loan default is total exclusion from the credit market - financial autarky - at all future dates. Consequently, loan default when middle-aged becomes very costly for any agent needing access to credit markets for the purposes of smoothening consumption. In such a setting, credit markets impose borrowing limits on individual borrowers consistent with their ability to pay that ensure no default occurs. The heterogeneity in inheritances translates into heterogeneity in the borrowing limits: endogenously, some young borrowers face a zero borrowing limit, some are partly constrained, while others are not constrained at all.

In the model economy, one's family lineage starts to matter in a big way. Inheritance-rich agents are allowed to borrow more; they, in turn, get more human capital and leave more for their children, more than what they received from their own parents. In such lineages, the market-imposed constraints matter less and less over generations; in the long-run, children in such families enjoy allocations attainable only via complete markets. For such lineages, the absence of a legal environment imposes no restrictions on their economic life. At the other end of the spectrum are inheritance-poor agents for whom the borrowing limits tighten as generations evolve; over some length of time, these families can get educational funding but eventually, the market shuts them out totally, and forever after. The absence of a legal environment critically affects their fortunes.

In the language of Mookherjee and Ray (2003), "the economy displays both equal and unequal steady states". Depending on the initial distribution, it is possible all lineages are attracted to either the zero-borrowing-limit steady state or to the unconstrained-borrowing steady state - there is long-run equality. It is also possible that some lineages end up at the zero-borrowing-limit steady state and the rest approach the unconstrained-borrowing steady state - there is complete long-run polarization. One thing is clear: long-run average human capital in such an economy is almost always lower than in an otherwise-identical economy with a perfect, costless-to-access legal system. This is one, hitherto unexplored, channel by which the rule of law matters for economic prosperity.

Our analysis informs the larger question, posed for example, by Banerjee and Newman (1991), Galor (1996), and others: "Does a market economy exacerbate the level of inequality 
in wealth and income, or does it merely reproduce variation in individual attributes?" In our model, history matters and variations in historical inheritances have both short-and long run consequences. Indeed, the market economy can exacerbate any existing fundamental inequality there may have been; over time, the entire wealth distribution may get polarized with mass resident only at the two extremes. What is more, minor differences in inheritances between lineages can create lasting, major differences in their ensuing family sagas.

The imperfection in the credit market is clearly to blame, for in its absence, under the complete markets of Arrow and Debreu, initial, fundamental inequality in our model would eventually self destruct. As is well understood, some sort of fixity, non-convexity, increasing returns - be it in preferences or technology - must be present if the long-run is to be history dependent. $^{2}$ For otherwise, under complete markets, initial differences cannot get magnified over time. On the face of it, no indivisibility of any sort appears evident in our model setup. $^{3}$ After all, agents do not face any restrictive caps or floors on how much they can invest in education. On closer inspection, however, it is apparent the fixity is concealed in the penalty: the inflexible, one-period exclusion from the credit market, the length of which is independent of the fundamentals underlying the loan contract.

Our work is very close in spirit to the seminal paper by Galor and Zeira (1993) who study how human capital investment funded by loans affects the progression of inequality in the presence of loan market imperfections. Their fundamental result is very similar: history matters, both in the short- and long run. Indeed, the shape of their by-now classic law of evolution for bequest-giving has an uncanny resemblance to ours, except ours has a bit more curvature. Two critical assumptions drive their result. First, the credit market is imperfect: the borrowing interest rate is exogenously assumed to be higher than the lending rate. Second, human capital investment is assumed to be indivisible; in effect, they assume a nonconvex technology. By way of contrast, note, in our setting, the borrowing and lending rates are identical and the credit market imperfection is endogenously derived. Moreover, human capital investment is not lumpy. The fact that borrowers cannot commit to loan repayments forces creditors to set up borrowing limits consonant with the borrower's interest to repay. These limits are not exogenously imposed, and yet, curiously enough, serve a role similar to that played by the exogenously-imposed, indivisible human capital investment in the Galor and Zeira (1993) model. ${ }^{4}$

\footnotetext{
${ }^{2}$ See for example Galor and Zeira (1993), Freeman (1996), Aghion and Bolton (1997), Picketty (1997), Mookherjee and Ray (2003).

${ }^{3}$ By introducing health capital that affects life expectancy into a two-period overlapping generations model, Chakraborty and Das (2005), in the absence of convex preferences and technologies, also explain the persistence of income inequality. In their model, poor parents are of poor health and thus have less incentive to invest in health and human capital. Consequently they leave less for their offspring.

${ }^{4}$ Bhattacharya (1998) studies the role of bequests in allowing entrepreneurs to supplement their own
} 
This paper is in line with recent work on borrowing constraints and human capital investment, but the focus in that literature is never on the effects of such constraints on the evolution of inequality in a market economy. De Gregorio (1996), Cartiglia (1997), Kaas and Zink (2007), Kitaura (2012), Jacobs and Yang (2013) among others consider exogenous borrowing constraints: individuals cannot borrow more than a fixed fraction of their current income, a case we consider parenthetically. In recent work, Andolfatto and Gervais (2006) and Wang (2014) study endogenous borrowing constraints in the context of optimal public education-pension policies while de la Croix and Michel (2007) focus more on issues relating to indeterminacy in such environments; both ignore the inequality angle. More recently, Sarigiannidou and Palivos (2012) attempt to provide the theoretical underpinnings of the Kuznets inverted-U hypothesis concerning inequality and per capita income in cross-section data. Like us, they study how endogenous borrowing constraints affect the evolution of the income distribution through the human capital investment channel. Apart from the fact that their focus is totally different, the difference is, in their setup, heterogeneity among agents lies in their innate learning aptitude. As a result, certain, low-ability agents will not want to invest in human capital. Over time, with development, the externality arising from knowledge spillovers induces all agents to invest in human capital.

The remainder of the paper is organized as follows. Section 2 presents the benchmark model where the credit market is complete. Section 3-4 study the case with imperfect credit markets and explores the dynamics of agents' bequest-giving. Section 5 discusses the intuition, and derives implications when certain assumptions are relaxed. Section 6 concludes.

\section{Benchmark Model: Complete market economy}

We consider a one-good, small open economy with time-invariant, exogenous factor prices, consisting of an infinite sequence of three period-lived overlapping generations; the three periods are labeled young, middle-age and old. There is also an initial old generation and an initial middle-aged generation in the economy. At each date $t=1,2, . ., \infty$, a continuum of agents with unit mass is born with the identical endowment profile $\left(\omega_{y}, \omega_{m}, \omega_{o}\right)$ where the subscripts $y, m$ and $o$ denote young, middle-aged, and old respectively. At any date, the new-born agents are identical in all respects except for the inheritance they will receive from their parents in the following period. The inaugural middle-aged generation is also assumed

internal financing of physical capital investment, thereby helping to mitigate the severity of the costly state verification problem. There the fixity comes from the indivisibility in the size of projects entrepreneurs can operate. 
to have received an inheritance derived from an initial bequest distribution, $\mathcal{G}\left(x_{0}\right)$, with finite support. This is the only exogenously-specified source of heterogeneity in the model.

When young, agents can access complete private markets - the benchmark case - to secure loans that finance acquisition of human capital. In their middle age, agents receive an inheritance from their parent, pay off their education loans, earn income using their accumulated human capital, consume, and save (or borrow) in the capital market at a fixed return, $R \geq 1$. (There is no alternative way to save, and the borrowing rate, the rate of interest on education loans, is also $R$.) When old, they consume a portion of their wealth, leave the remainder as a bequest to their single offspring, and die.

To obtain tractable results, we consider logarithmic utility function and the lifetime utility of a typical generation- $(t-1)$ agent is given by $U_{t-1}$ where

$$
U_{t-1} \equiv u\left(c_{m, t}\right)+\beta\left[u\left(c_{o, t+1}\right)+\phi u\left(x_{t+1}\right)\right], \beta>0, \phi>0 .
$$

Here, $c_{m, t}$ and $c_{o, t+1}$ denote the consumption during the middle age and old age of an agent born at date $t-1 ; x_{t+1}$ represent the bequest a generation- $(t-1)$ agent leaves his child when old (at $t+1) . \beta$ is a discount factor, and period-felicity $u(\cdot)$ is strictly increasing, concave and twice continuously differentiable. It is clear from the specification of (1) that the agent enjoys a 'warm glow' from leaving a bequest to his child; $\phi$ is the weight assigned to this warm glow.

The production technology for human capital is simple: $b_{t-1}$ units invested in education at date $t-1$ produces $f\left(b_{t-1}\right)$ units of human capital at the start of $t$; assume $f(\cdot)$ is strictly increasing and concave, with $f(0)=0$. Also assume $f(b)$ units of human capital generates $f(b)$ units of wage income; the wage rate is held fixed at unity.

Without loss of generality, assume $\omega_{y}=0$ implying the young must borrow to finance their education. The credit market is complete in the sense agents face no constraints on borrowing and saving. ${ }^{5}$ Moreover, loan contracts are easily and costlessly enforceable via a perfect legal system. In the benchmark case, we assume agents always commit to repaying their loans. Letting $s_{t}$ denote his saving in middle age, a typical agent's period budget constraints are given by

$$
\begin{aligned}
c_{m, t} & =\omega_{m}+f\left(b_{t-1}\right)-b_{t-1} R+x_{t}-s_{t}, \\
c_{o,+1} & =\omega_{o}+s_{t} R-x_{t+1} .
\end{aligned}
$$

Here, a generation- $(t-1)$ agent's middle-age income is the sum of his endowment, $\omega_{m}$, plus

\footnotetext{
${ }^{5}$ Agents do face standard non-negativity constraints on consumption. This, for example, implies their middle-age income net of loan repayment, $\omega_{m}+f\left(b_{t-1}\right)-b_{t-1} R$, cannot be negative if they have received zero inheritance. Similarly, $s_{t}$ cannot be "too negative".
} 
the wage income from his young-age human capital investment $\left(f\left(b_{t-1}\right)\right)$ net of the loan repayment expense $\left(b_{t-1} R\right)$, together with the inheritance he receives from his parent $\left(x_{t}\right)$. His old-age wealth is his old-age endowment, $\omega_{o}$, plus interest income from past saving, if any; a portion of this wealth is used to leave a bequest to his adult offspring.

We first derive the solution for optimal amount of educational investment $\left(b_{t-1}^{*}\right)$, which satisfies

$$
f^{\prime}\left(b_{t-1}^{*}\right)=R
$$

Equation (4) indicates that the optimal amount of education investment is achieved where the marginal return is equal to the marginal cost of education financing. Note that it also implies that each agent, irrespective of his inheritance, will borrow and invest the same at each date. Therefore, in all that follows, we use $b^{*}$ to denote the optimal human capital investment in the benchmark model. We then derive the solutions for optimal saving $\left(s_{t}^{*}\right)$ and optimal bequest $\left(x_{t+1}^{*}\right)$, and for the ease of subsequent analyses, we express them by the solutions for agents with family lineages $i$ :

$$
\begin{aligned}
s_{t}^{i, *} & =\frac{(1+\phi) \beta\left[\omega_{m}+f\left(b^{*}\right)+x_{t}^{i}-b^{*} R\right]-\frac{\omega_{o}}{R}}{1+\beta+\beta \phi}, \\
x_{t+1}^{i, *} & =\beta \phi \frac{R\left[\omega_{m}+f\left(b^{*}\right)+x_{t}^{i}-b^{*} R\right]+\omega_{o}}{1+\beta+\beta \phi} .
\end{aligned}
$$

Optimal saving and bequest-giving depend on the agent's lifetime income, which comprises of the return from human capital investment, and the inheritance $\left(x_{t}\right)$ he receives. Since agents $i$ and $j$ invest the same amount $\left(b^{*}\right)$ in education, any differences in saving and bequest-giving across them is entirely due to the difference between $x_{t}^{i}$ and $x_{t}^{j}$, the inheritance they receive. Equation (6) describes the evolution of bequest-giving for different family lineages. Since $x_{t+1}^{i, *}$ is linear in $x_{t}^{i}$ and $x_{t+1}^{i, *}$ is strictly positive when $x_{t}^{i}=0$, there exists a unique steady state if the following assumption holds:

Assumption $11+\beta+\beta \phi-\beta \phi R>0$.

In that case, the steady state solution, $\bar{x}^{i, *}$, is independent of $i$ and given by $\bar{x}^{*}$ where $\bar{x}^{*}$ is the average level of human capital investment in a complete-markets economy and is given by

$$
\bar{x}^{*}=\beta \phi \frac{R\left[\omega_{m}+f\left(b^{*}\right)-b^{*} R\right]+\omega_{o}}{1+\beta+\beta \phi-\beta \phi R}
$$

moreover, $\bar{x}^{*}$ is stable. This implies, in the complete markets economy, the initial bequest distribution, $\mathcal{G}\left(x_{0}\right)$, does not matter in the long run. Each family lineage, irrespective of 
their starting point $\left(x_{0}^{i}\right)$, ends up with the same level of bequest $\bar{x}^{*}$ and hence the same level of saving, $\bar{s}^{*}$; as a result, the long-run bequest and wealth distributions are degenerate.

The upshot is that in a complete-markets economy with full commitment to loan repayment and a perfect legal system, initial inequality does not survive. As we demonstrate below, once full commitment is compromised and the legal system is unable to enforce contracts, the job of preventing loan default falls on the market; as a result, things change quite dramatically.

\section{Borrowing-constrained economy}

In this section, we investigate an economy, otherwise identical to the one above, in which there is no legal system that can enforce compliance with loan contracts. Here, agents cannot commit to repaying their loans, and consequently, their ability to borrow against future income is limited by the absence of such commitment.

Following Kehoe and Levine (1993), all information is public, and in the event of default, the affected creditors cannot seize certain types of inalienable assets such as private endowments, inheritance or human capital, but can appropriate her current and future asset holdings. ${ }^{6}$ The only penalty creditors can impose is financial autarky, keeping the defaulter out of the credit market for the remainder of his life. For borrowers, the implicit cost of default is the foregone lifetime gains from participating in the credit market. ${ }^{7}$ Because all information is public, creditors allow an individual to borrow up to an amount that is in his own interest to repay. In other words, for all loan amounts less than that limit, the benefit of trading in the credit market exceeds the cost of autarkic consumption.

Now consider the individual's optimization problem in a borrowing-constrained economy. Suppose an agent born in period $t-1$ cannot borrow more than $\left(\bar{b}_{t-1}, \bar{s}_{t}\right)$ in youth and middle age. Taking these borrowing limits as exogenously given, the agent's problem is to maximize (1) subject to budget constraints (2)-(3) and the following borrowing constraints:

\footnotetext{
${ }^{6}$ Lochner and Monge-Naranjo (2011b, web appendix) state that even if creditors are allowed to garnish borrowers' wages in the enforcement of government student loans, they can only garnish up to $15 \%$ of wages. Thus, we think it is useful to assume that creditors cannot garnish defaulters' wages and relax it in the later discussions to provide policy implications.

${ }^{7}$ The setup is consistent with the private student lending in the U.S.. As mentioned in Lochner and MongeNaranjo (2011b, web appendix), "...enforcement of private student loans was regulated by U.S. bankruptcy code (Bankruptcy Abuse Prevention and Consumer Protection Act of 2005). Borrowers ling for bankruptcy under Chapter 7 must ... surrender any noncollateralized assets (above an exemption) in exchange for discharging all debts... Furthermore, bankruptcy shows up on an individual's credit report for ten years, limiting future access to credit...".
} 


$$
\begin{aligned}
b_{t-1} & \leq \bar{b}_{t-1}, \\
-s_{t} & \leq \bar{s}_{t} .
\end{aligned}
$$

The optimal allocation in a borrowing-constrained economy $\left(\widehat{c}_{m, t}, \widehat{c}_{o, t+1}, \widehat{b}_{t-1}, \widehat{s}_{t}, \widehat{x}_{t+1}\right)$ is characterized by (2)-(3) and the following Kuhn-Tucker conditions:

$$
\begin{aligned}
f^{\prime}\left(\widehat{b}_{t-1}\right) & \geq R,=\text { if } \widehat{b}_{t-1}<\bar{b}_{t-1}, \\
u^{\prime}\left(\widehat{c}_{m, t}\right) & \geq \beta R u^{\prime}\left(\widehat{c}_{o, t+1}\right),=\text { if }-\widehat{s}_{t}<\bar{s}_{t}, \\
u^{\prime}\left(\widehat{c}_{o, t+1}\right) & =\phi u^{\prime}\left(\widehat{x}_{t+1}\right) .
\end{aligned}
$$

(10) implies that if agents are borrowing constrained when young, the marginal return from their human capital investment is higher than its marginal cost. In this case, $\widehat{b}_{t-1}<b^{*}$ holds, which implies underinvestment in human capital.

We next show how the borrowing limits are endogenously determined. Notice that the borrowing limits are optimally set by the lenders, who know the borrower cannot credibly commit to paying back a loan. Their optimal lending decision is the solution to the problem that maximizes (1), subject to budget constraints (2)-(3) and the following individual rationality constraints (IRC).

$$
\begin{aligned}
\ln c_{m, t}+\beta\left[\ln c_{o, t+1}+\phi \ln x_{t+1}\right] \geq & \ln \left[\omega_{m}+f\left(b_{t-1}\right)+x_{t}\right] \\
& +\beta \ln \left(\frac{\omega_{o}}{1+\phi}\right)+\beta \phi \ln \left(\frac{\phi \omega_{o}}{1+\phi}\right), \\
\ln c_{o, t+1}+\phi \ln x_{t+1} \geq & \ln \left(\frac{\omega_{o}}{1+\phi}\right)+\phi \ln \left(\frac{\phi \omega_{o}}{1+\phi}\right) .
\end{aligned}
$$

The left-hand side of the two IRCs is the maximal continuation utility this agent receives if he repays the loan when middle aged and old, while the right-hand side is the one the agent receives if he defaults. Our assumptions imply that if the agent defaults, he gets to keep his inheritance and is also permitted to leave bequests - no restriction is imposed on the latter either. Satisfaction of these two IRCs ensures borrowers will always prefer repayment to default.

An implication of the $\operatorname{IRC}(2)$ is a non-negativity restriction on saving:

$$
s_{t} \geq 0
$$

This means that a middle-aged agent is allowed to save but not allowed to borrow, i.e., $\bar{s}_{t}=0$, the borrowing limit for a middle-aged agent. The intuition is that since an agent consumes everything in his old-age period, the penalty of exclusion from credit market in that period incurs no loss. As a result, if a middle-aged agent is allowed to borrow a positive amount, he will certainly default on his loan in old-age. In contrast, the complete-markets economy imposes no restriction on the sign of $s_{t}$. The inability of agents to commit to 
loan repayment and the absence of a legal enforcer makes every middle-aged generation borrowing-constrained.

We next solve the borrowing limit faced by the young agent. Let $V_{m}\left(b_{t-1}, x_{t}, R\right)$ denote the value function of a middle-aged agent who is born in period $t-1$, has borrowed $b_{t-1}$ when young, inherits bequest of $x_{t}$ and decides to repay the loan. $V_{m}\left(b_{t-1}, x_{t}, R\right)$ is the indirect utility function computed by

$$
\max _{\left\{c_{m, t}, c_{o, t+1}, x_{t+1} \mid b_{t-1}, x_{t}\right\}} \ln c_{m, t}+\beta\left[\ln c_{o, t+1}+\phi \ln x_{t+1}\right],
$$

subject to (13). According to $\operatorname{IRC}(1)$, the borrowing limit for a generation- $(t-1)$ agent that has inherited an bequest of $x_{t}, \bar{b}_{t-1}$, is determined from

$H\left(\bar{b}_{t-1}, x_{t}, R\right) \equiv V_{m}\left(\bar{b}_{t-1}, x_{t}, R\right)-\ln \left[\omega_{m}+f\left(\bar{b}_{t-1}\right)+x_{t}\right]-\beta \ln \left(\frac{\omega_{o}}{1+\phi}\right)-\beta \phi \ln \left(\frac{\phi \omega_{o}}{1+\phi}\right)=0$.

It is obvious $H\left(0, x_{t}, R\right)>0$ since allowing agents to smooth consumption against their lifetime income must weakly dominate utility under autarky. Evidently, as $b$ approaches infinity, agents will find it optimal to default, and hence, we have $H\left(\infty, x^{t-2}, R\right)<0$. Therefore, there must exist a $\bar{b}_{t-1} \geq 0$.

Note since creditors allow young agents to borrow only up to $\bar{b}_{t-1}$, an amount that is in the latter's self-interest to repay, the IRCs are satisfied and young borrowers will always repay the loan they receive; no default occurs in equilibrium. It is also important to note $\bar{b}_{t-1}$ is a function of $x_{t}$; as such, agents with different $x_{t}$ will face different borrowing limits. For some, this limit will not bind, i.e., the market will lend them $b^{*}$; for others, this limit will hurt.

Lemma 1 The borrowing limit for a generation- $(t-1)$ agent, $\bar{b}_{t-1}$, is increasing in $x_{t}$, his inheritance. That is, agents with bigger future inheritance are allowed to borrow more.

Proof. Please see the online version.

The basic intuition underlying Lemma 1 is that a larger inheritance in middle-age suggests two things to a creditor, a higher ability to repay and a greater willingness to repay given the more pressing need for consumption smoothing, all else same. Both these effects work in tandem and allow the creditor to ease the borrowing restrictions and yet avoid default.

Given a $x_{t}$ and the above-discussed borrowing constraints imposed on the young and middle aged, a generation- $(t-1)$ agent's optimal saving decision $\left(\widehat{s}_{t}\right)$ and optimal bequest- 
giving decision $\left(\widehat{x}_{t+1}\right)$ are given by

$$
\begin{aligned}
\widehat{s}_{t} & =\frac{(1+\phi) \beta R\left[\omega_{m}+f\left(\bar{b}_{t-1}\right)+x_{t}-\bar{b}_{t-1} R\right]-\omega_{o}}{1+\beta+\beta \phi}, \\
\widehat{x}_{t+1} & =\phi \frac{\beta R\left[\omega_{m}+f\left(\bar{b}_{t-1}\right)+x_{t}-\bar{b}_{t-1} R\right]+\beta \omega_{o}}{1+\beta+\beta \phi},
\end{aligned}
$$

if the agent is borrowing constrained when young, and are given by their complete market counterparts - (5)-(6) - if both borrowing limits are slack. It bears emphasis that $\bar{b}_{t-1}$ depends on $x_{t}$ and arises endogenously. Interestingly, the amount of bequest-giving depends on the borrowing limit as well.

Before we examine the bequest-dynamics of the borrowing-constrained economy, it is useful to discuss some properties of the borrowing limit, $\bar{b}_{t-1}$. First, notice that $V_{m}\left(b_{t-1}, x_{t}, R\right)$ can be equivalently defined as

$$
\max _{\left\{s_{t} \geq 0 \mid b_{t-1}, x_{t}\right\}} \ln \left[\omega_{m}+f\left(b_{t-1}\right)+x_{t}-R b_{t-1}-s_{t}\right]+\beta \ln \left(\frac{\omega_{o}+s_{t} R}{1+\phi}\right)+\beta \phi \ln \left(\phi \frac{\omega_{o}+s_{t} R}{1+\phi}\right) .
$$

From (14), it is evident that the borrowing limit for some young agents equals zero, i.e., $\bar{b}_{t-1}=0$, if and only if they are borrowing constrained in middle age, i.e., $\widehat{s}_{t}=0$. That means there exists young agents whose young-age and middle-age borrowing demands are simultaneously binding and equal to zero. This happens when $\partial U_{t-1} /\left.\partial s_{t}\right|_{b_{t-1}=s_{t}=0} \geq 0$ or by simplification $\omega_{o} /\left[(1+\phi)\left(\omega_{m}+x_{t}\right)\right] \geq \beta R$ holds. Under this configuration, a middle-aged agent wishes to borrow against his old-age income $\left(\widehat{s}_{t}<0\right)$ even if he incurred no debt in his youth. Such an agent would surely default on any youthful loan since the punishment of exclusion from the credit market in their middle-age (conditional upon default) imposes no hardship on such agents. Foreseeing this, no creditor will lend any amount to such agents, leading to $\bar{b}_{t-1}=0$. When $\omega_{o} /\left[(1+\phi)\left(\omega_{m}+x_{t}\right)\right]<\beta R$, the optimal saving of a middle-aged agent with no prior borrowing is positive, i.e., $\widehat{s}_{t}>0$. In this case, defaulting is costly for middle-aged agents, and, as noted by (14), creditors can always choose a strictly positive borrowing limit that ensures the agent indifferent between default and repayment.

In sum, there are three possible outcomes in the endogenously borrowing constrained economy. 1) $\omega_{o} /\left[(1+\phi)\left(\omega_{m}+x_{t}\right)\right] \geq \beta R$ : agents are borrowing constrained in youth and middle age. In this case, $\bar{b}_{t-1}=\widehat{s}_{t}=0$, and the economy is in autarky with no borrowing or lending in the credit market. 2) $\omega_{o} /\left[(1+\phi)\left(\omega_{m}+x_{t}\right)\right]<\beta R$ and agents are borrowing constrained only when young. In this case, borrowing constraints are slack for middle-aged agents, with $0<\bar{b}_{t-1}<b^{*}$ and $\widehat{s}_{t}>0$. 3) $\omega_{o} /\left[(1+\phi)\left(\omega_{m}+x_{t}\right)\right]<\beta R$ and both borrowing constraints are slack, yielding complete market solutions.

Notice that the condition $\omega_{o} /\left[(1+\phi)\left(\omega_{m}+x_{t}\right)\right]<\beta R$ depends on the size of $x_{t}$, which would determine the regimes of the economy. First, there exists a lower bound for inheritance, 
call it $x_{l}$, such that young agents with inheritance below $x_{l}$ are unable to borrow in the credit market (and hence, invest nothing in their education). For such agents, the borrowing limit is 0 . In other words, $\bar{b}_{t-1}(x)=0$ for any $x \leq x_{l}$. Evidently

$$
x_{l}=\frac{\omega_{o}}{\beta(1+\phi) R}-\omega_{m}
$$

Secondly, since $\bar{b}_{t-1}$ is increasing in $x$ (as shown in Lemma 1), there must exist a threshold value, $x_{h}$, such that the borrowing constraint is slack for any $x \geq x_{h}$. In other words, $\bar{b}(x)>b^{*}$ for $x>x_{h}$. By definition, $x_{h}$ is determined by $H\left(b^{*}, x_{h}, R\right) \equiv 0$, i.e., by solving

$$
\begin{aligned}
& \ln \left[\omega_{m}+f\left(b^{*}\right)+x_{h}-b^{*} R-\widehat{s}\left(b^{*}, x_{h}\right)\right]+\beta(1+\phi) \ln \left(\omega_{o}+\widehat{s}\left(b^{*}, x_{h}\right) R\right) \\
& =\ln \left[\omega_{m}+f\left(b^{*}\right)+x_{h}\right]+\beta(1+\phi) \ln \omega_{o} .
\end{aligned}
$$

Young agents with inheritance that exceeds $x_{h}$ can and will repay the unconstrained loan amount, $b^{*}$.

\section{Dynamics of the bequest distribution in the borrowing- constrained economy}

The two thresholds, $x_{l}$ and $x_{h}$, defined in (17)-(18), divide the bequest space into three ranges. 1) Inheritance-poor agents $\left(x_{j} \leq x_{l}\right)$ cannot borrow $(\bar{b}=0)$ to finance their human capital investment; neither can they borrow against their old-age income so as to smooth consumption. As such the consumption choices of agents from such family lineages coincide with those under autarky; in addition, they always leave the same constant fraction of their old-age endowment as bequest to their offspring. 2) Middle-range agents $\left(x_{l}<x_{j}<x_{h}\right)$ face a binding borrowing constraint for their educational borrowing when young; $\bar{b}$ is smaller than the unconstrained $b^{*}$. Since these agents will not default, they are allowed to save in middle age using the credit market, i.e., $\widehat{s}>0$. 3) The final group of agents $\left(x_{j} \geq x_{h}\right)$ are not constrained in any way; they can borrow to invest the first-best, unconstrained amount.

The discussion above can be summarized by writing out the law of motion for bequests of a generic family lineage $j$ :

$$
x_{t+1}^{j}=\left\{\begin{array}{cl}
\frac{\phi}{1+\phi} \omega_{o}, & \text { if } x_{t}^{j}<x_{l}: \text { no borrowing } \\
\beta \phi \frac{R\left[\omega_{m}+f\left(\bar{b}_{t-1}\right)+x_{t}^{j}-\bar{b}_{t-1} R\right]+\omega_{o}}{1+\beta+\beta \phi}, & \text { if } x_{l} \leq x_{t}^{j} \leq x_{h}: \text { borrowing-constrained } \\
\beta \phi \frac{R\left[\omega_{m}+f\left(b^{*}\right)+x_{t}^{j}-b^{*} R\right]+\omega_{o}}{1+\beta+\beta \phi}, & \text { if } x_{t}^{j}>x_{h} \quad: \text { borrowing-unconstrained }
\end{array}\right.
$$


Figure 1 illustrates one possible, but arguably the most interesting case, one that generates three steady states. ${ }^{8}$ First, if parameter configurations are such that $\phi \omega_{o} /(1+\phi)<x_{l}$ $\Leftrightarrow \omega_{m}<(1-\beta \phi R) \omega_{o} /(\beta R+\beta \phi R)$, the flat segment in Figure 1 intersects the 45 degree line from above. This suggests there exists a locally stable steady state, corresponding to the case where certain family lineages are completely excluded from the credit market and get no education, forever. Second, if $x_{h}<\bar{x}^{*}$, there exists a second steady state, $\bar{x}^{*}-$ see eq. (7). By Assumption 1, $\bar{x}^{*}$ is stable. Note the law of motion for bequests for the unconstrained agents $\left(x_{h}<\bar{x}^{*}\right)$ coincides with that in the benchmark case. Finally, $x_{t+1}$ is monotonically increasing in $x_{t}$ for $x_{t} \in\left[x_{l}, x_{h}\right]$ as

$$
\frac{\partial x_{t+1}}{\partial x_{t}}=\frac{\beta \phi R}{1+\beta+\beta \phi}\left[\left(f^{\prime}\left(\bar{b}_{t-1}\right)-R\right) \frac{\partial \bar{b}_{t-1}}{\partial x_{t}}+1\right]>0 .
$$

Since $x_{t+1}$ is continuous in $x_{t}$ for all $x_{t} \geq 0$, if the aforementioned two steady states exist, we must have $x_{t+1}<x_{l}$ when $x_{t}=x_{l}$ and $x_{t+1}>x_{h}$ when $x_{t}=x_{h}$. As a consequence, the second segment must intersect the 45 degree line from below. Thus, there exists a third steady state and it is locally unstable.

Proposition 1 If $\omega_{m}<(1-\beta \phi R) \omega_{o} /(\beta R+\beta \phi R)$ and $x_{h}<\bar{x}^{*}$, there exist three steadystate equilibria: an autarkic steady state $\left(\bar{x}_{1}\right)$ and two non-autarkic steady states $\left(\bar{x}_{2}, \bar{x}_{3}\right)$, one of which is unconstrained and identical to the complete market allocation $\left(\bar{x}_{3}=\bar{x}^{*}\right)$. Moreover, $\bar{x}_{1}$ and $\bar{x}_{3}$ are locally stable, $\bar{x}_{2}$ is locally unstable.

Proposition 1 suggests the evolution of bequest-giving within family lineages in the borrowing-constrained economy depends on the initial bequest distribution; both in the short- and long run. Specifically, lineages that start with an initial bequest of $x_{0}^{j}>\bar{x}_{2}$ are borrowing constrained; nevertheless, they invest in education, generation after generation. They also leave a bequest larger than the one they received. Eventually, bequest-giving of these lineages converges to that in the complete-market case. Lineages that start off with an

\footnotetext{
${ }^{8}$ The curvature for the second segment of Figure 1 is derived as follows. First, given (19), it can be shown that both when $x_{t}=x_{l}$ or $x_{t}=x_{h}$, we have $\partial x_{t+1} / \partial x_{t}=\beta \phi R /(1+\beta+\beta \phi)$. That is, the slopes at the two boundary points of the second segment are the same. Moreover, for $x_{t} \in\left(x_{l}, x_{h}\right)$, the slope of the curve is

$$
\frac{\partial x_{t+1}}{\partial x_{t}}=\frac{\phi \beta R}{1+\beta+\beta \phi} \frac{\omega_{m}+f\left(\bar{b}_{t-1}\right)+x_{t}-\bar{b}_{t-1} R-\widehat{s}_{t}}{\omega_{m}+f\left(\bar{b}_{t-1}\right)+x_{t}-f^{\prime}\left(\bar{b}_{t-1}\right)\left(\bar{b}_{t-1}+\widehat{s}_{t} / R\right)} .
$$

Since $f^{\prime}\left(\bar{b}_{t-1}\right) \geq R$ for $x_{t} \in\left[x_{l}, x_{h}\right]$, we must have

$$
\frac{\partial x_{t+1}}{\partial x_{t}}>\frac{\beta \phi R}{1+\beta+\beta \phi}
$$

for all $x_{t} \in\left(x_{l}, x_{h}\right)$. Since $\partial x_{t+1} / \partial x_{t}>0 \forall x_{t} \in\left(x_{l}, x_{h}\right)$, the second segment must be convex initially before turning concave.
} 


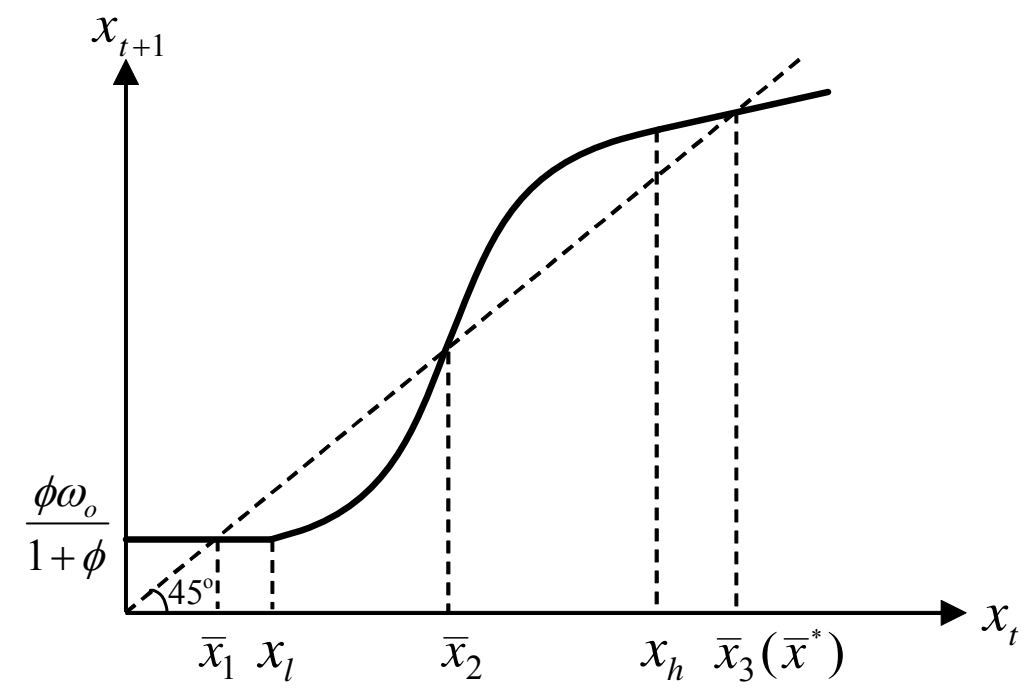

Figure 1: Bequest dynamics in the borrowing-constrained economy

initial bequest of $x_{l}<x_{0}^{j}<\bar{x}_{2}$ are also borrowing-constrained and do invest in human capital but only for a finite number of generations. Moreover, agents in these families leave less to their children than what they received from their parents. Eventually though, their bequestgiving falls below $x_{l}$ and from there on, no generation in that lineage gets any education. These lineages get stuck perpetually - a poverty trap. In the long run, there is complete polarization; all family lineages either converge to $\bar{x}_{1}$ or $\bar{x}_{3}$. Bequest-giving inequality increases over time.

At the heart of this result is the endogenous borrowing constraint which, in contrast to the complete-markets case, makes optimal lending contingent on the borrower's family lineage. All else same, a bigger inheritance indicates a higher ability and a greater willingness to repay allowing the creditor to lend more and yet avoid default. Above a certain threshold, $\bar{x}_{2}$, families can leave to their offspring than what they received from their parents. This, in turn, allows the children to leave even more to their children and so on, allowing for greater and greater human capital accumulation along the transition. The fate of families with inheritance below $\bar{x}_{2}$ is exactly the opposite. Each generation leaves less than what it received further curtailing the education investments of their descendants and leading to unrelenting impoverishment.

\section{Discussion of the assumptions}

We examine more closely the role of various assumptions in the legal environment. Of particular interest is examining whether the results derived in this paper are robust to more 
general penalties for debt defaulters.

\subsection{Partial garnishment of financial assets}

In the real world, while defaulters are usually barred from further borrowing, they are sometimes allowed to hold assets. In the borrowing constrained model of Section 3, it is assumed defaulters face complete exclusion from the credit market forever after. Put differently, in the setup of Section 3, we assumed full garnishment of financial assets. In that case, a natural question to ask is, do our previous results remain valid if the assumption of complete garnishment is relaxed. To answer this, we consider a setting in which creditors garnish only a proportion, $\theta<1$, of defaulters' financial assets; complete garnishment corresponds to $\theta=1$. We find that the previous results prevail. The discussion below explains why.

First, it is notable this change is equivalent to impose an interest rate $(1-\theta) R$ on the middle-aged defaulters. That implies the threshold inheritance below which agents cannot borrow when young becomes

$$
\widetilde{x}_{l}=\frac{\omega_{o}}{\beta(1+\phi)(1-\theta) R}-\omega_{m}>x_{l} .
$$

Clearly, for inheritance-poor agents $\left(x_{t} \leq \widetilde{x}_{l}\right)$, partial or complete garnishment makes no difference to them if they choose to default the youthful debts. Hence the law of motion of agent's bequest remains unchanged for $x_{t}<\widetilde{x}_{l}$ and the steady state $\bar{x}_{1}$ is retained.

Secondly, for agents who would save a positive amount in their middle age, partial garnishment reduces the cost of default thereby raising its likelihood. Foreseeing this, creditors are less willing to lend the same amount as under complete garnishment. As a result, on the one hand, the borrowing limit these agents face is tightened; on the other hand, a young agent needs a larger inheritance in order to borrow the same amount as under complete garnishment. The latter restriction implies the analog of $x_{h}$ - the threshold inheritance above which the borrowing limit becomes slack - rises: $\widetilde{x}_{h}>x_{h}$. It is easy to show if $\widetilde{x}_{h}<\bar{x}^{*}$, the underlying bequest dynamics remains qualitatively unchanged from that in Figure 1.

\subsection{Additional penalty: wage garnishment}

In this section, following Lochner and Monge (2011b) and Wang (2014), we consider the case where creditors can, conditional on default, garnish a fraction of borrowers' wage income in addition to their financial assets. ${ }^{9}$

\footnotetext{
${ }^{9}$ The results would remain unchanged if we allow lenders to partially garnish the inheritance the borrower receives from his parents.
} 
Let $\mu \leq 1$ be the proportion of defaulters' wage income that creditors can garnish. In this case, the lifetime utility of a middle-aged defaulter with inheritance $x_{t}$ and loan $b_{t-1}$ becomes

$$
\ln \left[\omega_{m}+(1-\mu) f\left(b_{t-1}\right)+x_{t}\right]+\beta \ln \left(\frac{\omega_{o}}{1+\phi}\right)+\beta \phi \ln \left(\frac{\phi \omega_{o}}{1+\phi}\right) .
$$

The new borrowing limit for him is solved by setting

$$
V_{m}\left(\bar{b}_{t-1}, x_{t}, R\right)-\ln \left[\omega_{m}+(1-\mu) f\left(\bar{b}_{t-1}\right)+x_{t}\right]-\beta \ln \left(\frac{\omega_{o}}{1+\phi}\right)-\beta \phi \ln \left(\frac{\phi \omega_{o}}{1+\phi}\right)=0
$$

It is easy to check that $\bar{b}_{t-1}$ exists and Lemma 1 holds.

The introduction of wage garnishment introduces several effects on the agent's borrowing limit. First, it raises the borrower's cost of default, implying middle-age agents are less likely to default and creditors are willing to lend more. Ceteris paribus, the borrowing limit for agents - those who were allowed to borrow in the benchmark model, those with inheritance $x_{t} \geq x_{l}-$ rises.

Secondly, with the additional penalty, agents who were barred from borrowing in the benchmark model, i.e., those with $\bar{b}\left(x_{t}\right)=0\left(x_{t} \leq x_{l}\right)$, can now borrow a positive amount if $\mu$ is large enough. The intuition is as follows. For a middle-aged agent with no desire to save, i.e., $\widehat{s}_{t}=0$, the penalty of credit market exclusion imposes no cost upon default. Therefore, no creditors will lend any amount to such agents. The wage-garnishment penalty, however, equips creditors with an additional and possibly effective penalty instrument. Consequently, these agents may be able to borrow a positive amount, i.e., $\bar{b}\left(x_{t}\right)>0$ for $x_{t}<x_{l}$. Whether they can do so depends on how severe the wage garnishment penalty $\mu$ is. Notice that since these agents prefer autarky when middle aged, the cost of default is the forgone wage income $(\mu f(b))$ and the gain is $R b$. It is easy to check that the very poor agents, whose optimal middle-age savings are binding, can borrow up to a positive amount only when $\mu>\mu_{l} \equiv R / f^{\prime}(0)$. In what follows, we use $\bar{b}_{l}$ to denote this borrowing limit. Clearly, the non-trivial amount of $\bar{b}_{l}$ satisfies $\mu f\left(\bar{b}_{l}\right)=R \bar{b}_{l}$ and is independent of the agent's bequest, $x_{t}$.

Thirdly, when $\mu$ is large enough, it is possible that $\bar{b}_{l} \geq b^{*} .{ }^{10}$ Let $\mu_{h}$ denote the threshold value of $\mu$ above which $\bar{b}_{l}>b^{*}$ holds, then $\mu_{h}$ solves

$$
\ln \left[\omega_{m}+f\left(b^{*}\right)-R b^{*}+x_{t}\right]=\ln \left[\omega_{m}+\left(1-\mu_{h}\right) f\left(b^{*}\right)+x_{t}\right] .
$$

Clearly $\mu_{h}=R b^{*} / f\left(b^{*}\right)$. This suggests when $\mu>\mu_{h}$, the borrowing limit for the young agent

\footnotetext{
${ }^{10}$ It is clear when $\mu=1, \bar{b}_{l}$ is solved by $f\left(\bar{b}_{l}\right)-R \bar{b}_{l}=0$ and it is strictly greater than $b^{*}$.
} 
is slack, i.e., $\bar{b}_{l}>b^{*}$, even when they have no desire to save in middle age.

The two thresholds, $\mu_{l}$ and $\mu_{h}$, divide the space of $\mu$ into three ranges. When the punishment of wage garnishment is not too severe $\left(\mu \in\left(0, \mu_{l}\right)\right), \bar{b}_{l}=0$ and $x_{l}$ thus remains unchanged as in (17). However, since the cost of default rises with wage garnishment, the threshold of bequest above which the borrowing limit becomes slack $\left(x_{h}\right)$ now falls. Nevertheless, the law of motion of bequests is as before; the results from the borrowingconstraints model of Section 3 prevail in this case.

When $\mu$ lies in the intermediate range $\left(\mu_{l}, \mu_{h}\right), x_{l}$ and $x_{h}$ both fall. Previous discussion has argued that agents with inheritance $x_{t}<x_{l}$ can borrow a constant, positive amount, $\bar{b}_{l}$. Since these agents do not wish to save in their middle age, the bequest they leave is fixed at $\phi \omega_{o} /(1+\phi)$. This implies the flat segment in Figure 1 continues to be present. Whether the flat segment intersects with the 45-degree line determines the existence of the lowest steady state. Note that the new $x_{l}$, denoted by $\breve{x}_{l}$, equals $x_{l}-f\left(\bar{b}_{l}\right)-R \bar{b}_{l}$ and $\bar{b}_{l}$ is increasing in $\mu$. Hence if $\mu$ is sufficiently small, we have three steady states and the same bequest dynamics as in the borrowing-constraints model of Section 3. If $\mu$ is sufficiently large, however, the flat segment does not intersect the 45-degree line and the only steady state is $\bar{x}^{*}$. In this case, poor agents are borrowing-constrained in the beginning, but their lineages face no constraint further along. The initial wealth distribution does not matter in the long run.

Finally, when the wage garnishment is sufficiently severe, i.e., $\mu \in\left(\mu_{h}, 1\right)$, the borrowing limit is slack for every agent and every agent can borrow $b^{*}$. In this case, the dynamics of the bequest distribution mimics those in the complete market: all agents have the same wealth in the long run and the initial wealth distribution matters no more.

\subsection{Exogenous borrowing constraint}

Finally, we consider a setting in which the borrowing constraint is exogenously imposed: young agents are simply allowed to borrow up to a fixed proportion, $\eta$, of their present value of lifetime income. That is, the borrowing limit $\bar{b}_{t-1}$ for young agents with inheritance $x_{t}$ becomes

$$
\bar{b}_{t-1}=\eta\left[\frac{\omega_{m}+f\left(\bar{b}_{t-1}\right)+x_{t}}{R}+\frac{\omega_{o}}{R^{2}}\right] .
$$

There exists a unique positive solution of $\bar{b}_{t-1} \cdot{ }^{11}$ Moreover, $\bar{b}_{t-1}$ is monotonically increasing in $x_{t}$. It implies there exists a threshold bequest $\check{x}_{h}$ such that $\bar{b}_{t-1} \geq b^{*}$ for any $x_{t}>\check{x}_{h}$.

\footnotetext{
${ }^{11}$ The left-hand side of (20) is linear in $b$ and the right-hand side is concave in $b$. Moreover, the left-hand side is smaller than the right-hand side, when evaluted at $b=0$.
} 
Here, $\check{x}_{h}$ is the solution to

$$
b^{*}=\eta\left[\frac{\omega_{m}+f\left(b^{*}\right)+\check{x}_{h}}{R}+\frac{\omega_{o}}{R^{2}}\right] .
$$

As discussed in the borrowing-constraints model of Section 3, the borrowing constraint is binding for agents with inheritance $x_{t} \leq \check{x}_{h}$, but slack for agents with higher inheritances. Two patterns emerge: when $x_{t} \leq \check{x}_{h}$, agents are borrowing-constrained and borrow at $\bar{b}_{t-1}\left(x_{t}\right)$; when $x_{t}>\check{x}_{h}$, agents are not constrained and borrow at $b^{*}$. We next characterize the curvature of the bequest dynamics when $x_{t} \leq \check{x}_{h}$. The law of motion for a generic family lineage $j$ becomes

$$
x_{t+1}^{j}=\left\{\begin{array}{cl}
\beta \phi \frac{R^{2}(1-\eta) \bar{b}_{t-1}\left(x_{t}^{j}\right)}{\eta(1+\beta+\beta \phi)}, & \text { if } x_{t}^{j} \leq \check{x}_{h}: \text { borrowing-constrained } \\
\beta \phi \frac{R\left[\omega_{m}+f\left(b^{*}\right)+x_{t}^{j}-b^{*} R\right]+\omega_{o}}{1+\beta+\beta \phi}, & \text { if } x_{t}^{j}>\check{x}_{h}: \text { borrowing-unconstrained }
\end{array} .\right.
$$

When $x_{t}^{j} \leq \check{x}_{h}$, we find

$$
\frac{\partial x_{t+1}^{j}}{\partial x_{t}^{j}}=\frac{\phi \beta R^{2}(1-\eta)}{\eta(1+\beta+\beta \phi)} \frac{\partial \bar{b}_{t-1}}{\partial x_{t}^{j}}=\frac{\phi \beta R^{2}(1-\eta)}{\eta(1+\beta+\beta \phi)} \frac{1}{R / \eta-f^{\prime}\left(\bar{b}_{t-1}\right)}>0 .
$$

Since $\bar{b}_{t-1}$ monotonically increases in $x_{t}^{j}$, it can be easily shown that $\partial^{2} x_{t+1}^{j} / \partial\left(x_{t}^{j}\right)^{2}<0$. Thus, $x_{t+1}^{j}$ is concave and monotonically increasing in $x_{t}^{j}$ when $x_{t}^{j} \leq \check{x}_{h}$. Since $x_{t+1}^{j}(0)>0$, there is a unique steady state, and this steady state is borrowing constrained if $\check{x}_{h}>\bar{x}^{*}$ and unconstrained if $\check{x}_{h} \leq \bar{x}^{*}$. In either scenario, the economy with an exogenous borrowing constraint totally mimics the complete market economy of Section 2 in the sense income inequality disappears in the long run. Clearly, what is important for long-run inequality is not the mere presence of borrowing constraints but the deeper reason why they exist, that is, the underlying weaknesses in the legal environment.

\section{Conclusion}

This paper studies how endogenous borrowing constraints affect human capital investment and the evolution of wealth inequality. To emphasize the role of endogenous borrowing constraints, we abstract away from ability differences and concentrate on heterogeneity in inheritance only. In the model economy, borrowing limits arise endogenously as a result of limited commitment: agents need to borrow to finance human capital investment but cannot commit to repaying their loans. Creditors can punish defaulters by banishing them permanently from the credit market. In equilibrium, loan default is prevented by imposing 
a borrowing limit tied to the borrower's inheritance.

The heterogeneity in inheritances translates into heterogeneity in the borrowing limits: some young borrowers face a zero borrowing limit, some are partly constrained, while others are unconstrained. Depending on the initial distribution of inheritances, it is possible all lineages are attracted to either the zero-borrowing-limit steady state or to the unconstrainedborrowing steady state - long-run equality. It is also possible some lineages end up at one steady state and the rest at the other - complete polarization. These results are fairly robust to changes in the legal environment. However, they are unattainable with an exogenous borrowing constraint.

The upshot is that credit markets, on their own, may not perpetuate inequality in the long run. Especially if such markets function within the larger gamut of social institutions such as a well-functioning justice system that stand ready to enforce contracts and disincentivize default. While the existing literature has rightly stressed the importance of improving credit market institutions for the purposes of promoting economic growth and reducing inequality, our work suggests such improvement, to be most effective, must be accompanied by betterments in the legal system. 


\section{References}

[1] Andolfatto, D., Gervais, M. (2006) Human capital investment and debt constraints. Review of Economic Dynamics 9(1), 52-67.

[2] Aghion, P., and P. Bolton. (1997) A theory of trickle-down growth and development. Review of Economic Studies, 64, 151-172.

[3] Azariadis, C., Lambertini, L. (2003) Endogenous debt constraints in life-cycle economies. Review of Economic Studies 70(3), 461-487.

[4] Banerjee, A. V., Newman, A. F. (1991) Risk-bearing and the theory of income distribution. Review of Economic Studies, 58, 211-35.

[5] Bhattacharya, J. (1998) Credit Market Imperfections, Income Distribution, and Capital Accumulation, Economic Theory 11(1), 171-200.

[6] Cartiglia, F. (1997) Credit constraints and human capital accumulation in the open economy. Journal of International Economics 43(1-2), 221-236.

[7] Chakraborty, S., Das, M. (2005) Mortality, human capital and persistent inequality. Journal of Economic Growth, 10(2), 159-192.

[8] De Gregorio, J. (1996) Borrowing constraints, human capital accumulation and growth. Journal of Monetary Economics 37(1), 49-71.

[9] De la Croix, D., Michel, P. (2007) Education and growth with endogenous debt constraints. Economic Theory 33(3), 509-530.

[10] Freeman, S. (1996) Equilibrium income inequality among identical agents. Journal of Political Economy, 104(5), 1047-64.

[11] Galor, O., Moav, O. (2004) From physical to human capital accumulation: inequality and the process of development. Review of Economic Studies 71(4), 1001-1026.

[12] Galor, O., Zeira, J. (1993) Income distribution and macroeconomics. Review of Economic Studies 60(1), 35-52.

[13] Galor, O. (1996) Convergence? inferences from theoretical models. Economic Journal, 106, 1056-1069.

[14] Jacobs, B., Yang, H. (2013) Second-best income taxation with endogenous human capital and borrowing constraints, CESifo Working Paper: Public Finance, No. 4155.

[15] Kass, L., Zink, S. (2007) Human capital and growth cycles. Economic Theory 31(1), 19-33.

[16] Kehoe, T., Levine, D. (1993) Debt-constrained asset markets. Review of Economic Studies $60(4), 865-888$.

[17] Kitaura, K. (2012) Education, borrowing constraints and growth, Economics Letters, $116(3), 575-578$.

[18] Lochner, L. Monge-Naranjo, A. (2011a) Credit and insurance for human capital investments. University of Western Ontario/Pennsylvania State University, Mimeo. 
[19] Lochner, L., Monge-Naranjo, A. (2011b) The nature of credit constraints and human capital. American Economic Review 101(6), 2487-2529.

[20] Mookherjee, D. and D. Ray (2003) Persistent inequality. Review of Economic Studies 70(2), 369-393.

[21] Piketty, T. (1997) The dynamics of the wealth distribution and the interest rate with credit rationing. Review of Economic Studies, 64(2), 173-189.

[22] Plug, E. J. S. and Vijverberg, W. (2005) Does family income matter for schooling outcomes? Using adoptees as a natural experiment. Economic Journal 115, 879-906.

[23] Sarigiannidou, M., Palivos, T. (2012) A modern theory of Kuznets' hypothesis, Texas Christian University Department of Economics Working Paper No. 12-02.

[24] Wang, M. (2014) Optimal education policies under endogenous borrowing constraints, Economic Theory 55(1), 135-159. 